\title{
PENGARUH ROLLING MASSAGE TERHADAP PRODUKSI ASI IBU NIFAS DI BPM ERNIATI DAN BPM IDA IRIANI KABUPATEN ACEH UTARA
}

\author{
Liana $^{1}$, Melia Hidayah ${ }^{2}$ \\ DIII Kebidanan, STIKes Getsempena Lhoksukon \\ liasst87@gmail.com ${ }^{1}$, meliahidayahsst01@gmail.com²
}

\begin{abstract}
Newborn babies need to get an early age, including ideal feeding. There is no single ideal food for newborns apart from breast milk. The World Health Organization (WHO) and the United Nations Children's Fund (UNICEF) recommend exclusive breastfeeding, namely breast milk given to babies from birth for 6 (six) months, without adding and or replacing with other foods or drinks. To increase breast milk production for postpartum mothers, one of the actions that can be taken to increase milk production is a rolling back massage which can provide a relaxed sensation for the mother, thereby smoothing the flow of nerves in the milk ducts in both breasts. This research design used a quasi experimental design method with two group post test design, where there are two groups of samples in the study that will be given treatment and a group that is not given treatment with a total sample of 32 samples with 2 groups. The results of this study are the interpretation of the Wilcoxon test results obtained by the value of $\alpha>P$ Value $(0.655<0.005)$, this means that there is no influence between rolling massage on the increase in breast milk production at BPM Erniati, Amd. Keb and BPM Ida Ariani, Amd, Keb, Aceh Utara District
\end{abstract}

Keywords $\quad$ :Increased Breast Milk Production, Rolling Massage

\begin{abstract}
ABSTRAK
Bayi baru lahir perlu mendapatkan perawatan yang optimal sejak dini, termasuk pemberian makanan yang ideal. Tidak ada satupun makanan yang ideal untuk bayi baru lahir selain ASI. World Health Organization (WHO) dan United Nations Children's Fund (UNICEF) menganjurkan pemberian ASI secara eksklusif yaitu ASI yang diberikan kepada bayi sejak dilahirkan selama 6 (enam) bulan, tanpa menambahkan dan atau mengganti dengan makanan atau minuman lain. Untuk meningkatkan produksi ASI padi ibu nifas, salah satu Tindakan yang dapat dilakukan untuk meningkatkan produksi ASI, adalah rolling massage punggung yang dapat memberikan sensasi rileks pada ibu, sehingga melancarkan aliran saraf saluran ASI pada kedua payudara. Rancangan penelitian ini menggunakan metode quasi experimental design dengan two group post test design, dimana terdapat dua kelompok sampel dalam penelitian yang akan diberikan perlakuan dan kelompok yang tidak diberikan perlakuan dengan jumlah sampel sebanyak 32 sampel dengan 2 kelompok. Hasil Uji Univariat menunjukan tidak terdapat perbedaan usia antara kelompok perlakuan dan kelompok control yang masing-masing dalam rentang usia dewasa (16-30 Tahun). Sedangkan untuk pekerjaan masing-masing kelompok dalam kategori ibu yang tidak bekerja (IRT) dan untuk pendidikan ibu dalam kategori pendidikan sedang (SMP-SMA). Hasil dari penelitian ini adalah interprestasi dari hasil uji Wilcoxon didapatkan nilai $\alpha>\mathrm{P}$ Value $(0,655<0,005)$ hasi ini berarti tidak terdapat pengaruh antara Rolling Massage Terhadap Terhadap Peningkatan Produksi ASI Ibu di BPM Erniati, Amd. Keb dan BPM Ida Ariani, Amd, Keb Kabupaten Aceh Utara
\end{abstract}

Kata Kunci : Peningkatan Produksi ASI. Rolling Massage

\section{PENDAHULUAN}

Bayi baru lahir perlu mendapatkan perawatan yang optimal sejak dini, termasuk pemberian makanan yang ideal. Tidak ada satupun makanan yang ideal untuk bayi baru lahir selain ASI. World Health Organization (WHO) dan United Nations 
Children's Fund (UNICEF) menganjurkan pemberian ASI secara eksklusif yaitu ASI yang diberikan kepada bayi sejak dilahirkan selama 6 (enam) bulan, tanpa menambahkan dan atau mengganti dengan makanan atau minuman lain (Thet MM, et., al (2016).

Pemberian ASI eksklusif selama 6 bulan pertama kehidupan bayi memiliki banyak kendala. Salah satu kenda yang menyebabkan ketidakberhasilan pemberian ASI eksklusif adalah ibu kurang percaya diri bahwa ASI yang dimiliki dapat mencakupi kebutuhan nutrisi bayinya, sehingga kondisi bayi menjadi kurang sehat bahkan menjadi malnutrisi (Badru, A R. (2018).

Faktor-faktor yang mempengaruhi produksi ASI antara lain: 1) makanan, apabila makanan yang ibu makan cukup akan gizi dan pola makan yang teratur ; 2) ketenangan jiwa dan pikiran, keadaan psikologis ibu yang tertekan, sedih dan tegang akan menurunkan volume ASI; 3) penggunaan alat kontrasepsi, penggunaan alat kontrasepsi pada ibu menyusui perlu diperhatikan agar tidak mengurangi produksi ASI; 4) perawatan payudara, bermanfaat merangsang payudara memengaruhi hipofise untuk mengeluarkan hormon prolaktin dan oksitosin; 5) anatomis payudara; 6) pola istirahat, apabila kondisi ibu terlalu capek, kurang istirahat maka ASI akan berkurang; 7) faktor isapan anak atau frekuensi penyusuan, semakin sering bayi menyusu pada payudara ibu, maka produksi dan pengeluaran ASI akan semakin banyak; 8) berat lahir bayi, bayi berat lahir rendah (BBLR) mempunyai kemampuan menghisap ASI yang lebih rendah dibandingkan bayi dengan berat lahir normal (> 2500 gr) ;9) produksi ASI yang kurang lancar (Marmi., 2012)

Pada pasca persalinan atau masa nifas, dalam waktu 24 jam produksi ASI seringkali tidak keluar atau hanya keluar sedikit. Hal ini disebabkan karena manajemen laktasi yang kurang bagus. Salah satu penyebab dari manajemen laktasi yang kurang bagus yaitu karena ibu kurang percaya diri bahwa ASI yang dimiliki cukup untuk bayinya (Marmi., 2012).

Untuk meningkatkan produksi ASI padi ibu nifas, salah satu Tindakan yang dapat dilakukan untuk meningkatkan produksi ASI, adalah rolling massage punggung yang dapat memberikan sensasi rileks pada ibu, sehingga melancarkan aliran saraf saluran ASI pada kedua payudara (Suryani, 2016).

Rolling massage punggung akan memberikan kenyamanan dan membuat rileks ibu karena massage dapat menstimulasi reflex oksitosin. Teknik pemijatan pada titik tertentu dapat menghilangkan sumbatan dalam darah dan energi di dalam tubuh akan kembali lancer (Suryani, 2016).

Berdasarkan hasil data riset kesehatan dasar (Riskesdas) 2013 menyatakan bahwa persentase proses bayi mulai mendapat ASI antara 1-6 jam sebesar 35,2\%, persentase proses bayi mulai mendapat ASI antara 7-23 jam sebesar3,7\%, persentase proses bayi mulai mendapat ASIantara 24-47 jam sebesar $13,0 \%$, persentase proses bayi mulai mendapat ASI lebih dari 47 jam sebesar $13,7 \% 4$.

Menurut Heny Ekawati (2017) dalam penelitiannya terkait efektivitas Rolling Masase pada ibu nifas terhadap produksi ASI mendapatkan hasil bahwa ada pengaruh antara Rolling Masase terhadap peningkatan produksi ASI dengan nilai $(\rho=0,001<\alpha=$ $0,05)$ ). Sedangkan menurut Elvika Shanti (2017) terdapat hubungan yang bermakna antara rolling masase dengan peningkatan berat badan bayi dengan nilai $(p=0.023<)$ produksi ASI (berat badan bayi) antara kelompok kontrol $(2687,07 \pm 160,155)$ dengan kelompok perlakuan $(2846,13 \pm$ 198,968).

Sedangkan untuk hasil observasi secara langsung yang dilakukan peneliti terlihat bahwa, dari ibu bersalin di BPM Erniati, Amd.Keb dan BPM Ida Iriani, S.Si.T masing-masing perwakilan sampel sebanyak 5 pasien didapatkan bahwa, produksi ASI ibu pada primigravidarum masih belum bisa 
keluar secara lancar. Oleh sebab itu, dalam hal ini peneliti sangat tertarik untuk melakukan penelitian tersebut agar nantinya hasil penelitian ini dapat meningkatkan kualitas hidup bayi, menurunkan angka kematian bayi dan mencegah Stanting dalam 1000 hari pertama.

Tujuan dari penelitian ini adalah peneliti ingin melihat seberapa besar pengaruh rolling massage punggung terhadap produksi ASI dibandingkan dengan teknik-teknik lainnya. Oleh sebab itu peneliti sangat tertarik untuk melakukan penelitian tentang pengaruh Rolling massage terhadap produksi ASI. Agar nantinya semua ibu dapat memberikan ASI secara eksklusif tanpa beralasan yang tidak jelas dan dapat dilakukan secara mandiri dirumah.

\section{METODE}

Rancangan penelitian ini menggunakan metode quasi experimental design dengan two group post test design, dimana terdapat dua kelompok sampel dalam penelitian yang akan diberikan perlakuan dan kelompok yang tidak diberikan perlakuan.

Penelitian telah dilakukan di BPM Erniati, Amd.Keb dan BPM Ida Iriani, S.Si.T Kabupaten Aceh Utara pada bulan Juni s/d September Tahun 2020.

Sampel penelitian ini adalah Ibu bersalin yang dibagi dalam 2 kelompok yang tiap masing-masing berjumlah $16 \mathrm{ibu}$ nifas di dua BPM.Teknik analisa data yang digunakan adalah : uji statistik dengan bantuan aplikasi SPSS untuk melihat seberapa besar pengaruh rolling massasse punggung terhadapn produksi ASI pada ibu nifas. Untuk menunjang hasil penelitian ada beberapa uji statistik yang digunakan antara lain:

\section{Analisa Data}

Analisis Univariat Dilakukan dengan statistic deskriptif untuk melihat distribusi frekuensi masing-masing variabel penelitian dan disajikan dalam bentuk tabel distribusi frekuensi. Analisis Bivariat Analisis digunakan untuk melihat pengaruh rolling massasse punggung terhadap produksi ASI pada kelompok perlakuan dan kontrol dengan menggunakan uji independent t-test dan paired sample $t$ test.

\section{HASIL}

\section{Analisa Univariat}

Tabel 1 (Perlakuan) Distribusi Usia Dalam Rolling Masase Terhadap Peningkatan Produksi ASI di BPM Erniati, Amd. Keb, dan BPM Ida Ariani, Amd, Keb Kabupaten Aceh Utara

\begin{tabular}{cccc}
\hline No & Usia & F & Persentase \\
\hline $\mathbf{1}$ & Lansia & 0 & $0 \%$ \\
$\mathbf{2}$ & Dewasa & 16 & $100 \%$ \\
$\mathbf{3}$ & Remaja & 0 & $0 \%$ \\
\hline & Total & 16 & $100.0 \%$ \\
\hline
\end{tabular}

Berdasarkan table 1 di atas dapat dilihat bahwa dari seluruh reponden masuk dalam rentang usia dewasa dengan persentase sebesar $100 \%$.

Tabel 2 (Perlakuan) Distribusi Pendidikan Dalam Rolling Masase Terhadap Peningkatan Produksi ASI di BPM Erniati, Amd. Keb, dan BPM Ida Ariani, Amd, Keb Kabupaten Aceh Utara

\begin{tabular}{cccc}
\hline No & Pendidikan & F & Persentase \\
\hline $\mathbf{1}$ & Tinggi & 2 & $12,5 \%$ \\
$\mathbf{2}$ & Sedang & 8 & $50,0 \%$ \\
$\mathbf{3}$ & Rendah & 6 & $37,5 \%$ \\
\hline & Total & 16 & $100.0 \%$
\end{tabular}

Berdasarkan Tabel 2 dapat dilihat bahwa dari 16 responden, Sebagian besar ibu berpendidikan sedang sebanyak 8 $(50,0 \%)$.

Tabel 3 (Perlakuan) Distribusi Pekerjaan Dalam Rolling Masase Terhadap Peningkatan Produksi ASI di BPM Erniati, Amd. Keb, dan BPM Ida Ariani, Amd, Keb Kabupaten Aceh Utara 


\begin{tabular}{cccc}
\hline No & Pekerjaan & F & Persentase \\
\hline $\mathbf{1}$ & Bekerja & 6 & $37,5 \%$ \\
$\mathbf{2}$ & Tidak Bekerja & 10 & $62,5 \%$ \\
& Total & 16 & $100.0 \%$ \\
\hline
\end{tabular}

Berdasarkan Tabel 5.3 di atas dapat dilihat bahwa, sebagian besar ibu yang tidak bekerja sebanyak $10(62,5 \%)$.

Tabel 4 (Tidak Perlakuan) Distribusi Usia Dalam Rolling Masase Terhadap Peningkatan Produksi ASI di BPM Erniati, Amd. Keb, dan BPM Ida Ariani, Amd, Keb Kabupaten Aceh Utara

\begin{tabular}{cccc}
\hline No & Usia & F & Persentase \\
\hline $\mathbf{1}$ & Lansia & 0 & $0 \%$ \\
$\mathbf{2}$ & Dewasa & 16 & $100 \%$ \\
$\mathbf{3}$ & Remaja & 0 & $0 \%$ \\
& Total & 16 & $100.0 \%$
\end{tabular}

Berdasarkan tabel 5.4 di atas dapat dilihat bahwa dari seluruh reponden masuk dalam rentang usia dewasa dengan persentase sebesar $100 \%$.

Tabel 5 (Tidak Perlakuan) Distribusi Pendidikan Dalam Rolling Masase Terhadap Peningkatan Produksi ASI di BPM Erniati, Amd. Keb, dan BPM Ida Ariani, Amd, Keb Kabupaten Aceh Utara

\begin{tabular}{cccc}
\hline No & Pendidikan & F & Persentase \\
\hline $\mathbf{1}$ & Tinggi & 2 & $12,5 \%$ \\
$\mathbf{2}$ & Sedang & 12 & $75,0 \%$ \\
$\mathbf{3}$ & Rendah & 2 & $12,5 \%$ \\
& Total & 16 & $100.0 \%$ \\
\hline
\end{tabular}

Berdasarkan Tabel 5 di atas dapat dilihat bahwa dari 16 responden, Mayoritas ibu berpendidikan sedang sebanyak 12 $(75,0 \%)$.

Tabel 6 (Tidak Perlakuan) Distribusi Pekerjaan Dalam Rolling Masase Terhadap Peningkatan Produksi ASI di BPM Erniati, Amd. Keb, dan BPM Ida Ariani, Amd, Keb Kabupaten Aceh Utara

\begin{tabular}{cccc}
\hline No & Pekerjaan & F & Persentase \\
\hline $\mathbf{1}$ & Bekerja & 4 & $25,0 \%$ \\
$\mathbf{2}$ & Tidak Bekerja & 12 & $75,0 \%$ \\
& Total & 16 & $100.0 \%$ \\
\hline
\end{tabular}

Berdasarkan Tabel 5.6 di atas dapat dilihat bahwa, Mayoritas ibu yang tidak bekerja sebanyak $12(75,0 \%)$.

\section{Analisa Bivariat}

Tabel 7 Distribusi pengaruh Rolling Massase Terhadap Peningkatan Produksi ASI Ibu di BPM Erniati, Amd. Keb,dan BPM Ida Ariani, Amd, Keb Kabupaten Aceh Utara

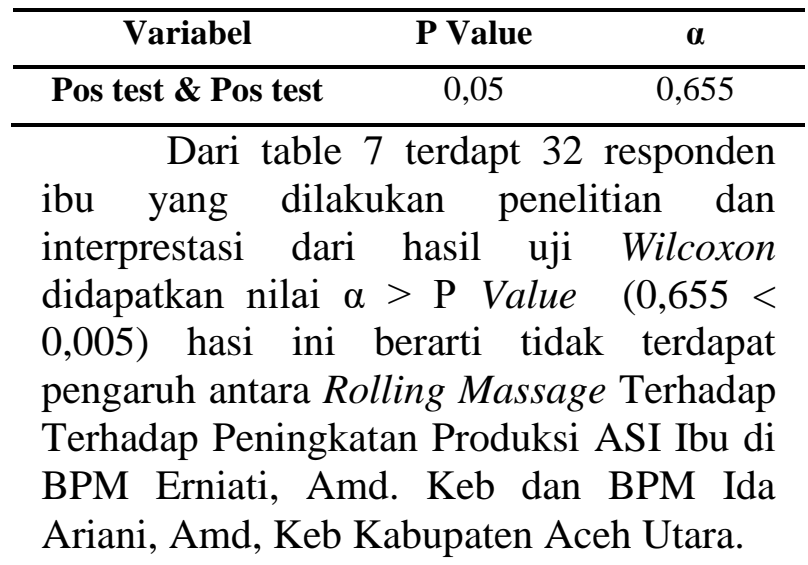

\section{PEMBAHASAN}

Berdasarkan hasil penelitian didapatkan hasil bahwa tidak terdapat hubungan yang kuat antara Rolling Masase dengan produksi ASI pada ibu nifas dengna nilai $(0,655<0,005)$.

Penelitian ini bertolak belakang dengan penelitian terdahulu seperti Heny Ekawati yang menyatakan hasil 0,001 $(\rho<$ $0,05)$ yang berarti ada pengaruh rolling massage punggung terhadap peningkatan produksi ASI pada Ibu nifas. Sedangkan menurut Dasmawati menyatakan hasil $\mathrm{P}$ $0,016(\rho<0,05)$ yang berarti memiliki pengaruh terhadap produksi ASI.

$$
\text { Rolling massage punggung }
$$
merupakan pemijatan pada tulang belakang (costae 5-6 sampai scapula dengan gerakan memutar) yang dilakukan pada ibu setelah melahirkan untuk membantu kerja hormon 
oksitosin dalam pengeluaran ASI, mempercepat saraf parasimpatis menyampaikan sinyal ke otak bagian belakang untuk merangsang kerja oksitosin dalam mengalirkan ASI agar keluar.

Tindakan massage rolling punggung dapat memengaruhi hormon prolaktin yang berfungsi sebagai stimulus produksi ASI pada ibu selama menyusui. Tindakan ini juga dapat membuat rileks pada ibu dan melancarkan aliran saraf serta saluran ASI pada kedua payudara.

Hasil penelitian diatas menyatakan tidak adanya pengaruh antara Rolling Masase dengan produksi ASI yang dapat disampaikan oleh peneliti ialah factor kecemasan dan dukungan keluarga terdekat (orang tua atau suami) pernyataan peneliti didukung oleh (Abu-Abbas, et al., 2016) Menyusui merupakan bagian terpenting bagi bayi dalam tahap awal kehidupannya. Menyusui bukan hanya keterlibatan antara ibu dan bayi saja, melainkan ayah memiliki peranan yang penting dalam proses menyusui (Tseng, 2015).

Dukungan ayah berpengaruh dalam proses menyusui. Ibu akan merasa aman saat menyusui, apabila ibu mendapat dukungan dan partisipasi dari pasanganya yang lebih aktif dan efektif (Lima, et al., 2016).

Dukungan yang kurang diberikan oleh keluarga akan mengakibatkan kecemasan ibu dalam proses menyusui dan produktivitatas ASI. Kecemasan

\section{KESIMPULAN}

Kesimpulan dari penelitian ini adalah tidak terdapat pengaruh antara pemberian pijatan punggung atau rolling masase terhadap penngkatan produksi ASI pada ibu nifas.

\section{DAFTAR PUSTAKA}

Badru, A R. (2018) Perbedaan Massage Woolwich Dan Massage Rolling (Punggung) Terhadap Peningkatan Produksi Asi Pada Ibu Postpartum. J-
HESTECH, Vol. 1 No. 1, Tahun 2018, 43- 49

Buku Pedoman Pemberdayaan Ibu Menyusui Pada Program Asi Eksklusif Tahun 2017.

Ekawati, H (2016) Pengaruh Rolling Massage

Punggung Terhadap Peningkatan

Produksi Asi Pada Ibu Nifas. Medical

Technology and Public Health Journal (MTPH Journal) 69-78

Dinata, F. Perawatan Masa Nifas. Retrieved Oktober 11, 2016, from RS Azra:

Hamranani. (2010). Pengaruh Pijat Oksitosin Terhadap Involusi Uteri Pada Ibu Postpartum dengan Persalinan Lama di Rumah Sakit Wilayah Kabupaten Klaten. Tesis Tidak Dipublikasikan, UI, Depok, Jakarta

Hastono SP, (2016) Analisis Data Pada Bidang Kesehatan. Jakarta. PT. Raja Grafindo Persada

Kemenkes RI. Riset Kesehatan Dasar. Jakarta: Kementerian Kesehatan RI; 2018.

Kemenkes RI, (2013) Riset Kesehatan Dasar (RISKESDAS) Balitbang KemenKes RI.

Marmi. Asuhan Kebidanan Pada Masa Nifas "Peurperium Care". Yogyakarta: Pustaka Pelajar. 2012.

Mufdlilah, Pemberdayaan pada kelompok ayah asi dalam pemanfaatan teknologi oksitomom. Jurnal Pengabdian Masyarakat Aipkema (JPMA) Vol 1, No. 1, Februari 2020, pp. 8-13

Nasrullah D, (2014) Etika dan HUkum Keperawatan. Jakarta. CV. Trans Info Media

Peraturan Menteri Kesehatan Republik Indonesia Nomor 15 Tahun 2013, tentang tata cara Penyediaan Fasilitas Khusus Menyusui Dan/Atau Memerah Air Susu Ibu

Suryani. Pengaruh Pijat Oksitosin terhadap Prosuksi ASI pada Ibu Post Partum di BPM Wilayah Kabupaten Klaten. Jurnal Keperawatan. 2013.

Thet MM, Khaing EE, DiamondSmith N, Sudhinaraset M, Oo S, Aung T. Barriers to exclusive breastfeeding in the Ayeyarwaddy Region in Myanmar: Qualitative findings from mothers, grandmothers, and husbands. Appetite. 2016;96:62-69 